tise and instrumentation can help enhance environmental testing laboratories productivity in all facets of wastewater and drinking water analysis, including volatiles, semivolatiles, pesticides and the analysis of trace metals;

- application notes relevant to the environmental water analysis industry, including "Analysis of Organophosphate Pesticides by LC-MS," "Analysis of
Mercury in Wastewater by ICP-MS," "Volatiles by Purge-and-Trap GC/ MS," and many more applications designed to help meet technical, regulatory and business goals; and product literature for Agilent's industry-leading line of GC, GC-MS, LC, LC-MS and ICP-MS instrumentation.

The Water Analysis Information Kit is available free of charge from any Agilent sales office worldwide.

Please contact:

Sarah Perceval

HCC De Facto Group ple

Tel.: 020/74963300

Fax: $020 / 74963355$

E-Mail: s.perceval@hccdefacto.com

\title{
Errata
}

\section{Separation and Determination of Rutin and Quercetin in the Flowers of Sophora japonica L. by Capillary Electrophoresis with Electrochemical Detection}

by Xiangjun Li / Yuping Zhang / Zhuobin Yuan

published in Chromatographia 2002, 55, February (No. 3/4), pp. 243-246

There was an error in the structure (Figure 1) published on p. 243. Please find below the correct version of the structure.<smiles>O=c1c(OC2OC(COC3OC4OC(O4)C(O)C3O)C(O)C(O)C(O)C2O)c(-c2ccc(O)c(O)c2)oc2cc(O)cc(O)c12</smiles><smiles>O=c1c(O)c(-c2ccc(O)c(O)c2)oc2cc(O)cc(O)c12</smiles>

Figure 1. The structures of the analytes: I rutin; II quercetin

The authors 